\title{
Effect of online social networking on employee productivity
}

\author{
A. Ferreira * \\ Centre for Information and Knowledge Management \\ University of Johannesburg \\ Johannesburg, South Africa \\ aferreira@uj.ac.za \\ T. du Plessis \\ Department of Information and Knowledge Management \\ University of Johannesburg \\ Johannesburg, South Africa \\ tduplessis@uj.ac.za
}

The popularity of social networking sites is relatively recent and the effect of online social networking (OSN) on employee productivity has not received much scholarly attention. The reason most likely lies in the social nature of social networking sites and OSN, which is assumed to have a negative effect on employee productivity and not bear organisational benefit. This reseach investigated recent Internet developments as seen in the social Web and specifically investigated the effect of OSN on employee productivity and what some of the consequences would be if employees were allowed unrestricted access to these networks. The findings concerning the nature of employees' OSN activities, employees' attitude or perceptions with regard to OSN in the workplace and how OSN can contribute or affect the productivity of employees are discussed in this article. Some of the basic misconceptions regarding OSN are highlighted and it is concluded that this technology can be used to increase collaboration between individuals who share a common interest or goal. Increased collaboration will stimulate knowledge sharing between individuals, with the possible effect of increased productivity. However, the risks associated with OSN should be noted, such as loss of privacy, bandwidth and storage consumption, exposure to malware and lower employee productivity.

Key words: Online social networking, employee productivity, Web 2.0, social capital, communities of practice

Received 28 January 2009; accepted March 2009

\section{Contents}

1. Introduction

2. Productivity and social networking in the modern economy

2.1 Capital factors in the modern economy

2.2 Rise of the social Web 
3. Online social networking

3.1 Online social networking and communities of practice

3.2 Advantages and risks of online social networking

3.3 Measuring the effect of online social networking

4. Research approach and findings

4.1 Data collection and processing procedure

4.2 Research findings

5. Conclusion

6. References

\section{Introduction}

For some years employers have had to deal with issues concerning employees' Internet use via organisational information and communication technology (ICT) infrastructures. Many organisations effectively employed acceptable use policies combined with other defense technologies to manage Internet access and use. In the organisational context the problems associated with online social networking (OSN) technology as well as the nature of the content on such sites present employers with a dilemma. On the other hand, the opportunities that OSN can present to organisations should be investigated in order to make informed decisions before simply discarding this type of communication and collaboration technology.

Similar to other organisations, tertiary education institutions apply and benefit from various communication and collaboration technologies. As with organisations in general, employees at tertiary education institutions have varying computer and Internet literacy and skill levels. This study aimed to establish whether employees of a South African university had previously used, were using, or would be interested in using online social networks in a professional environment and what effect the unrestricted use of OSN technology would possibly have on the productivity of these employees.

\section{Productivity and social networking in the modern economy}

Bernolak (1997:204) defined productivity as 'how much and how well we produce from resources used. If we produce more or better goods from the same resources, we increase productivity. Or if we produce the same goods from lesser resources, we also increase productivity'. In this article, 'productivity' refers to the time spent by an employee actively executing the job he or she was hired to do, in order to produce the desired outcomes expected from the employees' job description.

Recent studies, for example, Golder, Wilkinson and Huberman (2007), Arvanitis and Loukis (in press) and Coyle and Vaughn (2008:13-17) concur that social networks are typical characterisations of human behaviour to fulfil the need to communicate and connect with people they know, meet new people who share a common interest, collaborate, participate and share information and knowledge as well as gain new knowledge. Generally, these are also the reasons why individuals engage in social behaviour via the Internet. To many, the Internet provides effective social networking opportunities and their online behaviour includes building individual relationships, expanding their personal network of friends, finding people who have had similar experiences, discussing common topics of interest, dating and finding potential life partners, staying connected to old friends or distant family and virtually meeting peers, including work colleagues, to discuss current issues or topics of interest. 


\subsection{Capital factors in the modern economy}

In the modern economy, Boase, Horrigan, Wellman and Rainie (2006:26), Acquaah (2008:1235), Arvanitis and Loukis (2008); Shalley and Perry-Smith (2008:23-24), and Wong (2008:591-614) identify some of the 'new' factors that are becoming increasingly important, namely:

- Human capital, that is the knowledge, skills and capabilities that people possess

- Social capital, that is the relationships between people and the collective wealth contained therein

- Organisational capital, that is the new workplace management skills and knowledge acquired through learning within the modern organisation, which simultaneously and continuously adapts and learns to sustain performance

- Intellectual capital, that is the knowledge people possess that can be exploited for financial gain or any other useful purpose that might be advantageous to a company or cause

- Network capital, that is the contacts individuals draw on as a source of trusted information. This usually happens in an environment where people are confronted with institutions and rules, typically in a work environment, which forms part of problemsolving processes.

Combined, these factors can be referred to as 'knowledge capital', which refers to people as key organisational assets, because knowledge - that is valuable knowledge - exists mainly in individuals. People should therefore be the main focus of the knowledge-based economy, as they are the most valuable resource it has. Since the individual is the main focus of the knowledge-based economy, effective interaction between individuals is of great importance to stakeholders. The Internet has aided such interaction since its inception, and the flexibility of the World-Wide Web (the Web) has a unique capacity to 'break down boundaries of distance, language and domains of knowledge' (Berners-Lee, 2007:3). In the following section, the rise of the social Web and its applications will be briefly discussed.

\subsection{Rise of the social Web}

Since 2004 the term 'Web 2.0' has been used to describe the new applications and sites that were rapidly emerging in the existing Web environment (Anderson 2007:5). However, to discourage the misconception that these 'new' technologies are part of a 'separate' Web, the term 'social Web' is used to describe the interactive technologies that form part of the socalled Web 2.0 technologies. Web 2.0 technologies include blogs, wikis, folksonomies, podcasts, RSS and online social networks.

\section{Online social networks and social networking}

The concept of social networking is not new. Human interaction inherently promotes the formation of networks through social contact (Tapscott and Williams 2007:10).

Collaboration used to take place on a much smaller scale between relatives, friends and associates in households and communities. The present situation has changed substantially and today one rarely finds an organisation that functions without group collaboration and accordingly applies ICT in its collaboration space. In this space, social networking technology, for example, allows members to create personal profiles and network with other members, as well as with other organisations. Members network by adding other members as 'friends', posting public and private messages, participating in discussion forums and engaging in other forms of digitally mediated social interactions (Vander Veer 2008). Through the development of OSN technologies, it is now possible to network much quicker and reach a much larger expert audience. 


\section{Online social networks and human capital}

Social networking is common human behaviour, but the question arises: Do social networks add value to organisations? With specific reference to 'productivity', Arvanitis and Loukis (2008) investigated the link between ICT, human capital, workplace organisation and labour productivity. This was a comparative study based on firm-level data for Greece and Switzerland. Their study showed that although the use of ICT in Greek firms has led to positive productivity effects, the full productivity potential was not reached because human capital was not efficiently combined with technology. Similarly, Arvanitis and Loukis (2008) found that:

'The decentralization of some competencies has positive productivity effects, but this potential is not fully exploited due to inefficient combination with human capital. Swiss firms, on the other hand, seem to be able to exploit the potential of technology and decentralization through the combination of these factors with appropriate human skills, which in turn enables a higher level exploitation of ICT and a more successful decentralization of competencies.'

From the above quote it is clear that the effective combination of human capital and technology is required to increase productivity. To this point it has been established that a focus on human capital, that is what people know, will contribute to an organisation's productivity. Organisations have to optimise this human capital by facilitating the interaction of communities and networks through, for example, social networking sites and business customised OSN technology. This is necessary to increase what people know, how they perform and how they apply their knowledge and energy in the organisational context and specifically within their communities of practice.

\section{Online social networking}

'Communities of practice', also known as CoPs or 'communities of interest' are '[g]roups of people who share a passion for something that they know how to do, and who interact regularly in order to learn how to do it better' (Wenger 2004:2). Boothby (2006:1) argues that today's knowledge worker can work efficiently in large virtual teams, and social networking sites create such an electronic platform. Wenger (2004:2) and Bryan, Matson and Weiss (2007) concur and add that groups of people, who interact regularly, such as virtual teams, are bound to improve their skills through knowledge sharing. Therefore, notice should be taken to knowledge workers of today who not only function efficiently in large virtual teams, but thrive in such an environment to an extent where they advance their knowledge sharing skills. If knowledge sharing can be increased by a virtual CoP, then social networking sites may prove to be the catalyst to promote interaction (Boyd and Ellison, 2007:211; Ryberg and Larsen, 2008:103-115).

Considering the potential of virtual teams interacting within a CoP by utilising the OSN platform, the effect may be an increase in productivity of those employees who actively search and employ their list of contacts as well as others' linked-in profiles and their contacts and by updating and growing their own list of contacts. If these 'connected individuals' spend time interacting with other individuals who possess knowledge about the relevant working environment, increased knowledge sharing is likely to take place. With this in mind, the potential positive effect of virtual CoPs is further investigated.

\subsection{Online social networking and communities of practice}


Productivity was described above as the time spent by an employee actively executing the job he or she was hired to do, in order to produce the desired outcomes expected from the employees' job description. Productivity refers to how well an individual performs. Research by Groysberg and Lee $(2008: 1123)$ show that individual top performers do not 'own' their performance, but that the 'quality of colleagues' in the organisation also significantly affects top performers' ability to maintain their performance. Thus, in an organisational context, value can be found in attracting and developing individuals who hold specialised knowledge, but that value can further be promoted by encouraging the social networks that enable the sharing of knowledge between these individuals. Lesser and Storck (2001:832) and Bartlett and Ghoshal (2002:38) explain how: by connecting these individuals a CoP is formed, which allows and encourages members to engage in sharing and learning based on their common interests. To this Khanna and New (2008:795) and Hong, Kianto and Kyläheiko (2008:196-202) add the importance of optimal use of the social Web to enhance knowledge work in a culture and generation diverse organisation. This is important in order to increase employee satisfaction and to foster individual and organisational performance. OSN technology may aid knowledge work in a diverse organisation and foster individual and organisational performance through collaboration; however the risks associated with OSN are manifold.

\subsection{Advantages and risks of online social networking}

Social networks function in the online environment through social networking sites, that is, technology that allows people to set up profiles, link to other individuals' profiles and view, navigate and interact with others in the social network. Lange (2008:361) views the linking of profiles together with the ability to view the resulting connections on others' profiles as the most tangible mechanisms reflecting existing social networks. Boyd and Ellison (2007:211) add that this technology allows people to articulate their relationship to others in a way that is visible to anyone who can access their profile. Being linked or connected to others can lead to potential benefits such as improved collaboration and information sharing, greater productivity and enhanced communications among coworkers, business partners and customers. KPMG (2007:2), Barker (2008:6-14), Bernoff and Li (2008:42) and Violino (2008:12-13) review recent studies of OSN in the workplace and conclude that OSN permits a robust blend of member profile and contact information, rich presence information, collaborative document creation, distribution tracking and other features that 'build a pulse' inside the organisation. In this environment, individuals know who knows who, what each member is currently involved in and how they can be reached. In short, OSN provides a simpler and more intuitive approach for members of the same community of employees to find each other based on complementary knowledge or need for knowledge.

However, OSN is not without risks. The European Network and Information Security Agency (2007:3-16), Hathi (2008:9), Perkins (2008:44), Star Technology (2008:2) and Violino (2008:13-15) summarise some of the risks as follows:

- OSN spurs social activity and is associated with developing addictive behaviour; if not managed properly it will result in a decline in employee productivity.

- OSN poses privacy issues and poses security risks such as identity fraud.

- OSN may result in secondary data collection, that is the indirect derivation of data from existing sources.

- OSN may lead to social networking spam, that is the propagation of unsolicited messages.

- OSN holds the risk of corporate espionage, that is organisations can expose their intellectual property and other proprietary information to the outside world or to people within the organisation with negative result.

- OSN may expose members to malware thereby introducing viruses, worms and 
spyware to the organisation's ICT infrastructure.

- OSN results in bandwidth and storage consumption. Many social network members share pictures, music, videos, high-definition movies and other large files.

Many individuals who use the social Web do so at work for both non-work and work-related purposes. Even though the above list of risks is not inclusive it suffices to stress the need to understand the effect of OSN in the workplace.

\subsection{Measuring the effect of online social networking}

Of all measurement instruments in business, Ward (2006) regards the measurement of return on investment (ROI) as the most important. In some organisations ROI is everything whereas other organisations aim to also measure employee satisfaction and productivity. To this extent Ward suggests the adaptation and integration of OSN technology into the organisation's intranet to provide employees with a social platfo rm for communication, collaboration and innovation. Some of the quantifiable outcomes to be measured would include, for example, paper use, hardware cost, headcount and sales figures. Softer outcomes are less simple to measure and include, for example, customer satisfaction, employee satisfaction and employee productivity.

Employee productivity and how it is affected by OSN was the focus of this study. There are many productivity attributes and other issues associated with human resource management and human performance measurement. However, these attributes fell beyond the research scope, which aimed to determine the oppor tunities and risks concerning OSN in the organisation and its effect on employee productivity.

\section{Research approach and findings}

To address the topics mentioned in the preceding sections, the following research problem was formulated: What is the effect of social networking on employee productivity within organisations, specifically tertiary educational institutions? Sub-problems were identified, aimed at investigating what online social networks are; whether these networks link individuals in communities in a useful manner; what global and national OSN trends exist; what some of the consequences would be if employees were allowed access to these networks without restriction; how OSN can contribute to the productivity of an organisation; and what benefit an organisation would reap from an organisation-specific online social network aimed at social networking among its employees. The target population was the employees of a South African university; the accessible population to which the findings were generalised was the Faculty of Management. A probability sample was conducted by drawing a stratified random sample.

\subsection{Data collection and processing procedure}

The data collection procedure followed a sequence in which exploration was followed by quantitative measurement, which was in turn followed by a qualitative analytical phase. The empirical study was carried out by performing interviews with key individuals and conducting a formal questionnaire aimed at measuring the target group's knowledge and use of various popular OSN sites. The formal questionnaire was made accessible to the 183 Faculty of Management employees. Upon the closure of the questionnaire, the data was processed by the Statistics Consultation Department of the university. A total of 89 responses were successfully captured, rendering a response rate of $48,6 \%$. 


\subsection{Research findings}

To establish the focus of each respondent's position the first section of the survey enquired about each respondent's type of appointment. Emphasis was placed on four main categories of appointment, namely permanent and temporary staff members, as well as academic and administrative staff members. Figure 1 illustrates the appointment levels of the sample of which the majority were permanent academic staff $(47,7 \%)$ and permanent administrative staff $(25 \%)$.

Figure 1 Nature of appointment

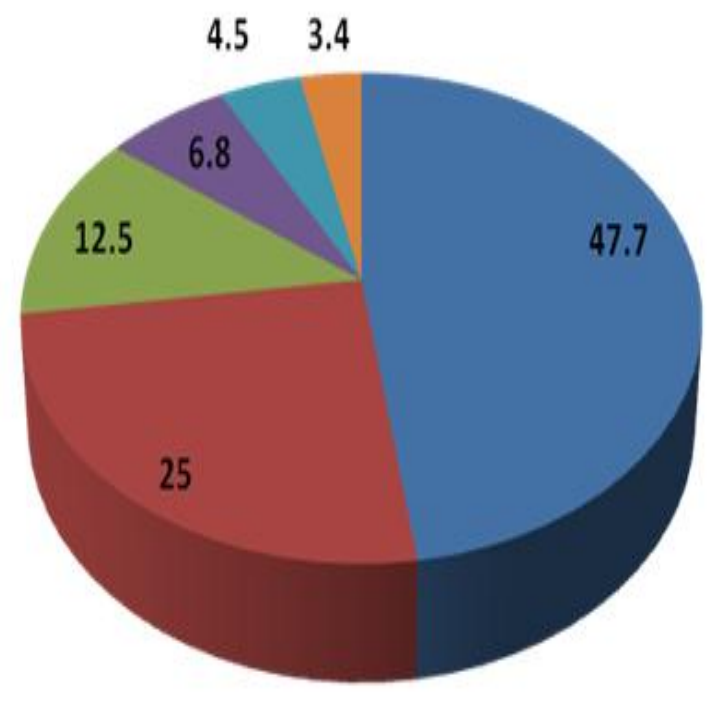

- Permanent Academic Staff (47.7\%)

- Permanent Administrative Staff (25\%)

Temporary Administrative Staff (12.5\%)

Temporary Academic Staff (6.8\%)

- Permanent Administrative Staff (Manager) (4.5\%)

- Permanent Academic Staff (HOD) (3.4\%)

The next survey section was dedicated towards establishing whether the respondents used online social networks, how much time they spent if they did engage in OSN and what their opinions and preferences regarding this technology were. This question was included in the survey to establish the respondent's familiarity with OSN sites. The four sites mentioned in the list provided were YouTube, MySpace, Facebook and LinkedIn.

As portrayed in Figure 2, 12,4\% of the sample did not recognise any one of the four popular OSN sites mentioned. Facebook proved to be the most recognised site $(82 \%)$ and LinkedIn was the least recognised site within this sample (18\%). YouTube and MySpace seemed to be similarly popular.

Figure 2 Recognised online social networking sites 


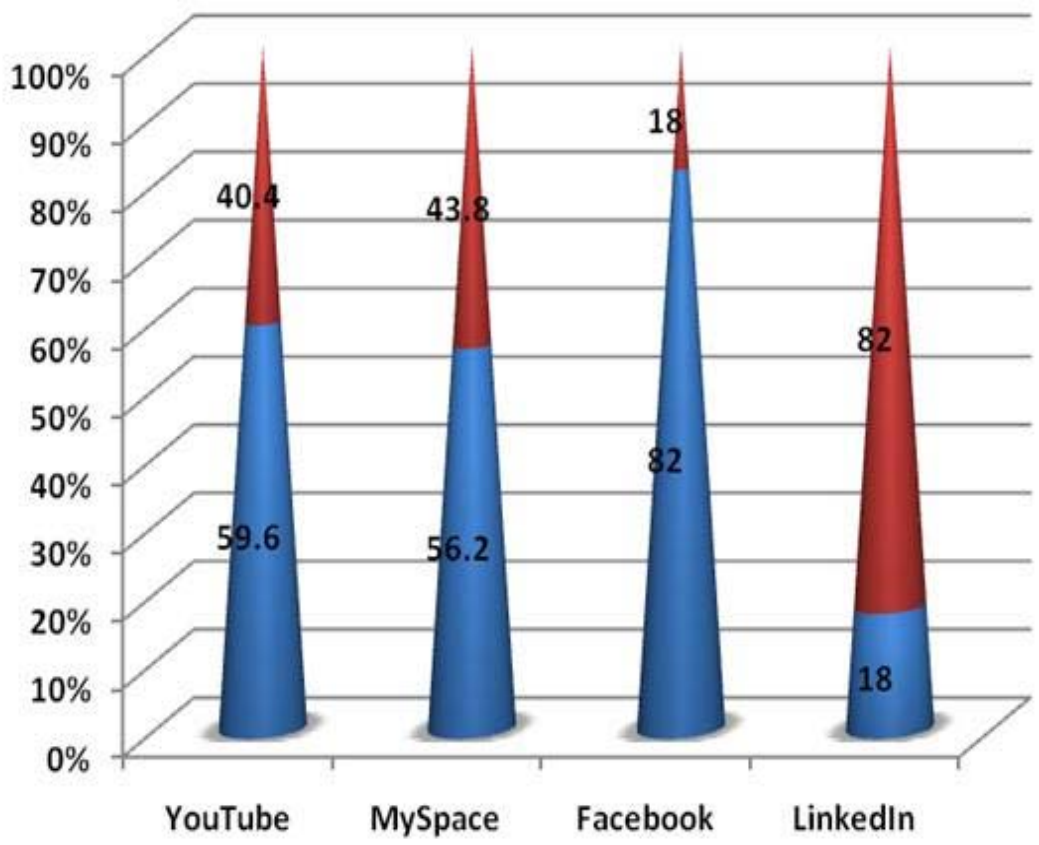

Do not recognise

$\square$ Recognise

It was also determined whether respondents visited the mentioned OSN sites. Those who did visit these sites were $55,2 \%$, whereas $44,8 \%$ of the respondents did not visit these sites at all. The next question aimed at determining the frequency of visits to OSN sites (Figure 3). Respondents also had the option to indicate whether they visited any other OSN sites not featured on the list. However, none of the other sites the respondents mentioned were OSN sites, but fell in other categories of the social Web. They were, for example, Blogspot, Flickr and Skype.

Figure 3 Frequency of visits to online social networking sites

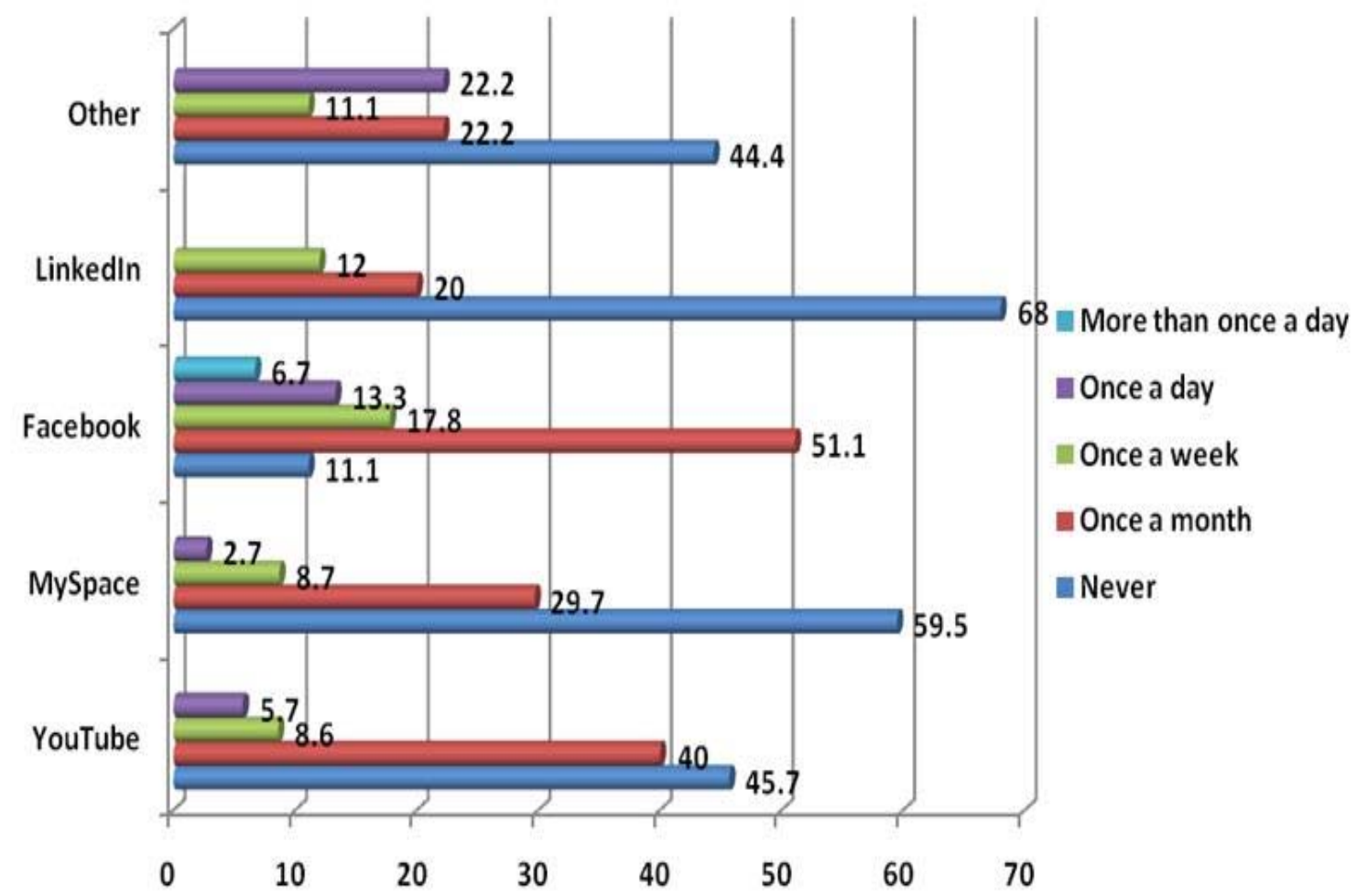

Regarding the frequency of visits to OSN sites, respondents indicated that Facebook was the site most frequently visited. It was visited more than once a day by $6,7 \%$ of the respondents, 
whereas none of the other sites were visited more than once a day. The least visited site was LinkedIn (68\%), followed by MySpace (59,5\%) and YouTube (45,7\%). Respondents' preferences may have been influenced by the contrasting nature of the listed OSN sites, for instance, the social focus of Facebook compared to the business focus of LinkedIn. This may indicate that OSN technology was applied more for social purposes than to conduct or advance respondents' business or daily work functions. The findings also indicated that a large section of the sample was willing to visit an online social network on either a daily or weekly basis, which signified an opportunity of virtual interaction within the organisation. If employees experienced the value of OSN for personal purposes they would probably also value a similar network aimed at their organisation in particular.

Figure 4 Access to online social networking sites

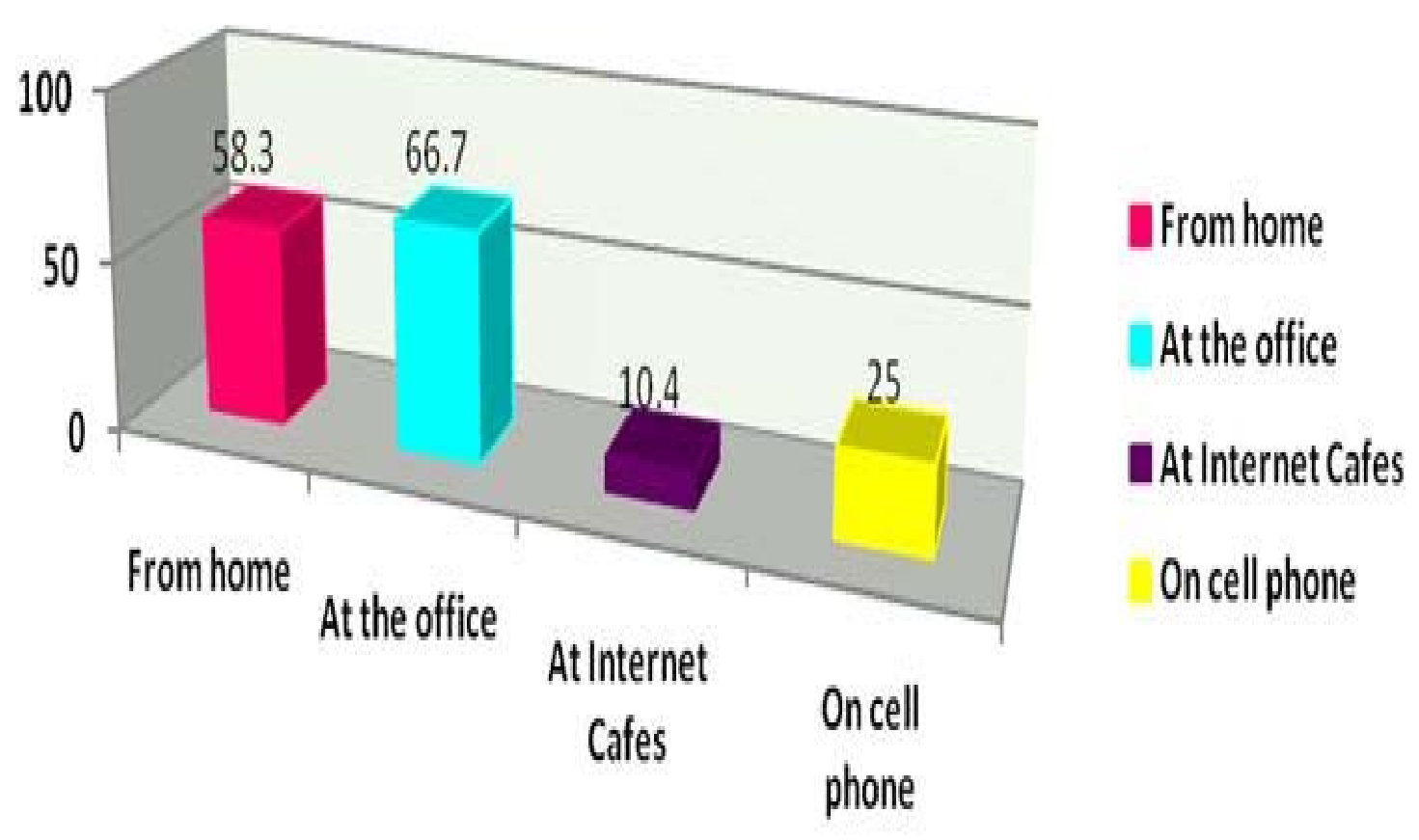

The survey next aimed at establishing whether respondents engaged in OSN more often from their office computer, indicating that these visits were most likely done during office hours; or from home, Internet cafes or via their cell phones. The results (Figure 4) showed that $66,7 \%$ of the respondents visited OSN sites from the office, while $58,3 \%$ of the respondents visited these sites from home. The other options proved to be the less popular, with $25 \%$ of respondents who indicated that they visited OSN sites via their cell phones and $10,4 \%$ of respondents who accessed these sites from Internet cafes. The fact that $66,7 \%$ of the respondents visited OSN sites during office hours led to the following suppositions which are supported by the findings of the literature review:

- Considering the risks associated with OSN sites, the high percentage of respondents accessing these sites from their office computers poses a threat to the organisation. The need to investigate and implement means to protect the individual and the organisation's ICT infrastructure against these risks is emphasised.

- OSN technology, applied in the organisational context, has the potential to boost employee performance. However, if faced with restrictions in accessing the social Web, some employees will leave a company to work in an environment that more closely match the way they run the rest of their lives (Condon 2007). From the findings it seemed that many respondents engaged in OSN at work. The organisation 
should exploit this opportunity and direct this activity to the organisation's advantage.

The purpose of this study was to discover what effect OSN may have on employee productivity. A reliable indicator of whether OSN was applied for work-related purposes was to determine the reasons why respondents used the technology (Figure 5).

Figure 5 Utilisation of online social networking sites

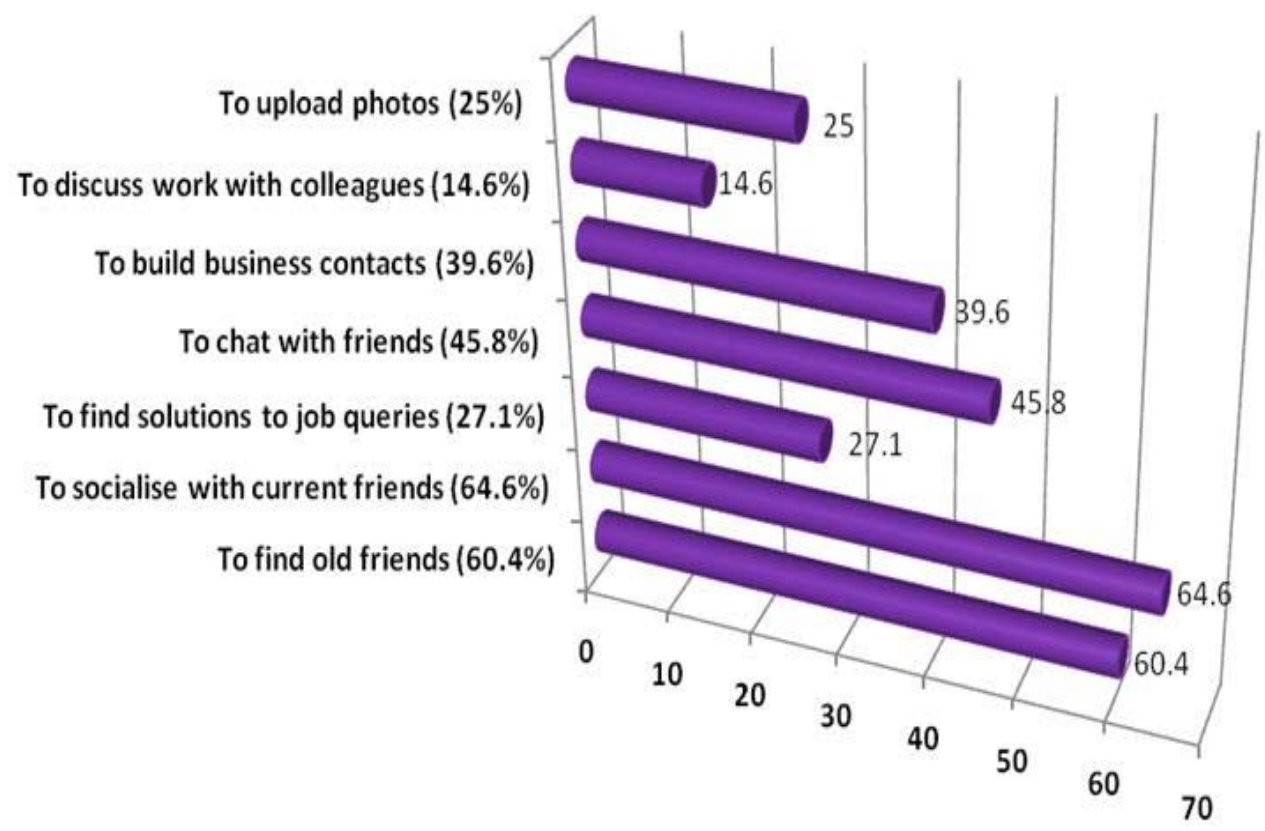

Respondents indicated that socialising with friends was the most popular reason for visiting OSN sites $(64,6 \%)$. The discussion of work-related issues with colleagues was the least selected option $(14,6 \%)$. From these results it seemed that OSN was generally not applied in a work-related manner. The assumption was made that the most value that was added to the respondents' daily lives regarding OSN sites happened on a social level. It could be that many respondents had not yet realised the potential value that OSN technology might add on a professional level. However, some respondents did indicate its value towards building business contacts $(39,6 \%)$ and to find solutions to job queries $(27,1 \%)$.

The last section of the survey aimed at determining respondents' attitude and perceptions towards OSN. A question consisting of ten statements was presented to respondents who had to rank each statement according to a Likert scale that assessed the degree to which respondents agreed or disagreed with each statement. These statements were derived from the literature review and are listed in Table 1 below.

Table 1 Determining respondents' attitude and perceptions regarding OSN

\begin{tabular}{|l|l|}
\hline 1 & $\begin{array}{l}\text { OSN encourages people to share knowledge and } \\
\text { expertise }\end{array}$ \\
\hline 2 & OSN lowers the productivity of employees \\
\hline 3 & $\begin{array}{l}\text { I have to have extensive knowledge about } \\
\text { Internet applications to participate in OSN }\end{array}$ \\
\hline & \\
\hline
\end{tabular}




\begin{tabular}{|l|l|}
4 & $\begin{array}{l}\text { OSN contributes to the intellectual capital of an } \\
\text { organisation (intellectual capital is people's } \\
\text { knowledge that can be exploited for financial } \\
\text { gain or any other useful purpose that might be } \\
\text { advantageous to a company or cause) }\end{array}$ \\
\hline 5 & $\begin{array}{l}\text { OSN sites are addictive (meaning that these sites } \\
\text { may negatively influence the way you normally } \\
\text { function to an extent that is detrimental to you) }\end{array}$ \\
\hline 6 & $\begin{array}{l}\text { OSN sites should be blocked by a company's IT } \\
\text { department }\end{array}$ \\
\hline 7 & $\begin{array}{l}\text { OSN encourages innovation through } \\
\text { collaboration }\end{array}$ \\
\hline 8 & $\begin{array}{l}\text { OSN is a tool designed for teenagers and } \\
\text { students }\end{array}$ \\
\hline 9 & $\begin{array}{l}\text { Using e-mail is just as effective as participating } \\
\text { in OSN }\end{array}$ \\
\hline 10 & $\begin{array}{l}\text { An organisational OSN site, specifically aimed } \\
\text { at personnel, will allow me to perform my day- } \\
\text { to-day work functions more efficiently }\end{array}$ \\
\hline
\end{tabular}

Respondents were first prompted to give their opinion on the probability of OSN encouraging the sharing of knowledge and expertise between individuals. Respondents either agreed $(45,8 \%)$ or strongly agreed $(24,1 \%)$ that OSN encouraged people to share knowledge and expertise (Figure 5). This positive attitude was resonated in the findings of the literature review regarding the sharing of knowledge among individuals who shared a common interest. The result to Statement 1 indicated that respondents recognised the value of OSN in terms of knowledge sharing. Combined with the results portrayed in Figure 4, it was surmised that the majority of the respondents would utilise OSN for this purpose in the organisational context. Forming CoPs and in turn sharing knowledge have advantages such as decreasing the learning curve of new employees, responding more rapidly to customer needs and inquiries, reducing rework and preventing work duplication - all of which aid employee productivity.

In Statement 2, respondents had to indicate whether they were of the opinion that OSN lowered the productivity of employees. Respondents were divided in their opinion: Of the respondents, $33,7 \%$ indicated that they disagreed with the notion that OSN lowered the productivity of employees, whereas the same percentage of respondents agreed with the notion. Compared to the preceding findings these results seemed to be ambiguous. A possible explanation for this divide could be the preconceived notion that OSN was regarded as a time-wasting activity and that the respondents may have reacted on this notion as opposed to reacting on the fact that they were applying OSN to share knowledge, an activity that ultimately leads to increased employee productivity. The respondents of this survey therefore acknowledged the hypothetical value of OSN, but were not convinced that this technology did not place employee productivity at risk.

Figure 6 Attitude and perception regarding online social networking related statements 


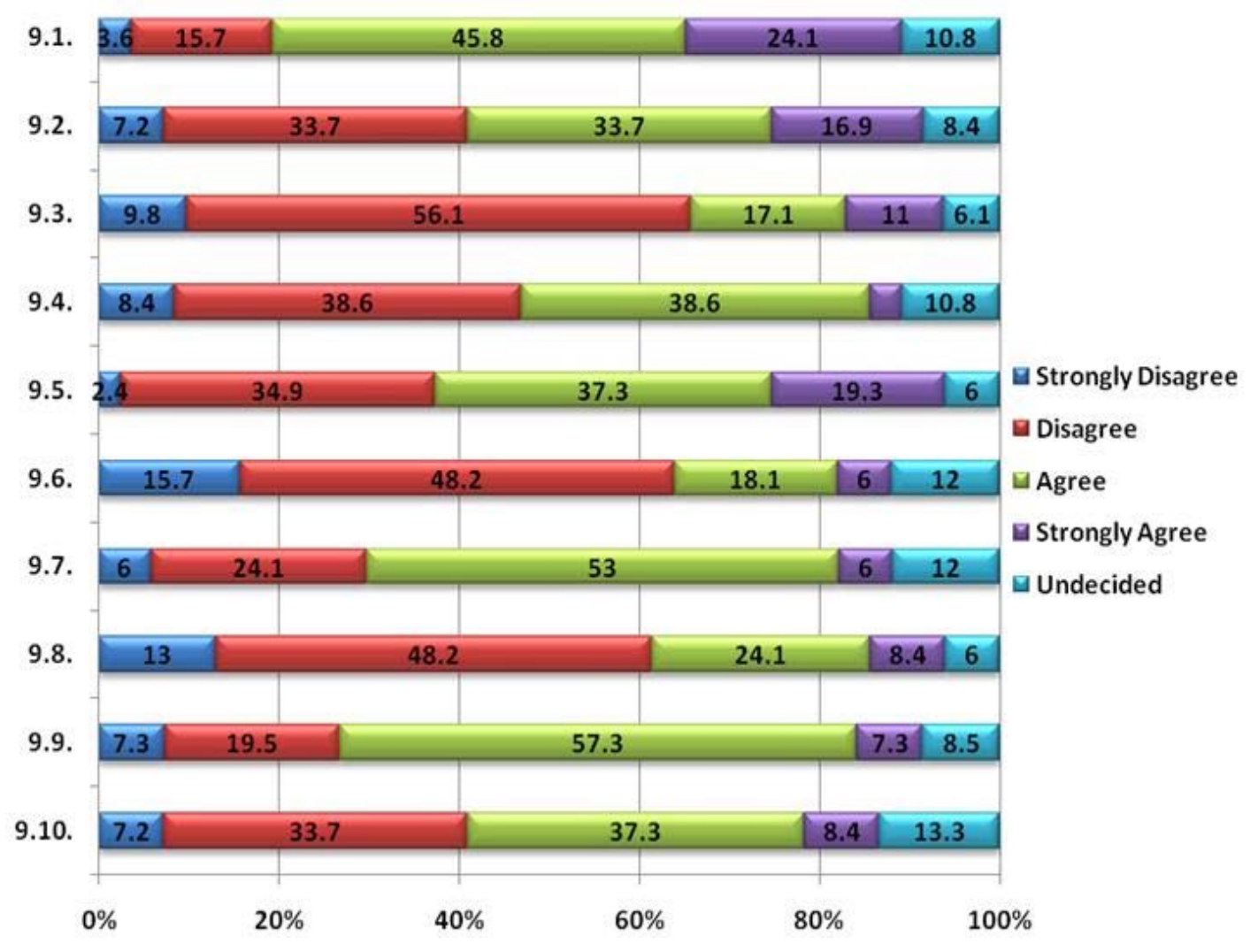

Statement 3 aimed at establishing the respondents' perceptions of the technical difficulty of OSN. Misconceptions might deter respondents from participation in organisational OSN. This however did not seem to be a major problem with $65,9 \%$ of respondents who disagreed or strongly disagreed that extensive knowledge about Internet applications was needed to participate in OSN. This should encourage an organisation to employ OSN technology to its advantage.

The next statement was aimed at determining whether OSN contributed to the intellectual capital of an organisation. The results showed that many respondents disagreed $(38,6 \%)$ and strongly disagreed $(8,4 \%)$ or were undecided $(10,8 \%)$ whether OSN contributed to the intellectual capital of their organisation. It seemed the majority disagreed with this notion. However, the respondents who agreed $(38,6 \%)$ and strongly agreed $(3,6 \%)$ that OSN contributed to the intellectual capital of their organisation were not significantly less than those who disagreed with this statement. Still, the majority of respondents disagreed with this statement. An explanation for the reaction to this statement may be a lack of understanding regarding the term 'intellectual capital'. A definition of intellectual capital was provided, however, the respondents were not necessarily familiar with the topic and the possibility existed that the concept of intellectual capital being transformed into traditional, monetary capital was not a logical progression of effects to the respondents.

Statement 5 tested whether respondents experienced OSN as being addictive. The most widely held opinion was that OSN sites were addictive. Respondents either agreed (37,3\%) or strongly agreed $(19,3 \%)$ that OSN was in fact addictive. This result emphasised the need to support employees in applying technology in ways that did not negatively influence the way they normally function at work. This could entail restricted access to OSN sites, which received attention in Statement 6. The results, however, indicated that many respondents disagreed $(48,2 \%)$ or strongly disagreed $(15,7 \%)$ that access to OSN sites should be blocked by an organisation's IT department. On the other hand, some respondents agreed $(18,1 \%)$ or strongly agreed $(6,0 \%)$ that access should be blocked. Although the majority or respondents rejected the idea, a considerable percentage did see due cause for an organisation's IT 
department to block access to OSN sites. Given the risks and the advantages of OSN at work, organisations should consider measures to protect the organisation's ICT infrastructure.

The next statement explored respondents' perceptions as to whether OSN encouraged innovation through collaboration. Respondents predominantly agreed and strongly agreed (59\%) that OSN could encourage innovation. This attitude should be exploited by organisations. If employees showed interest in participating in organisational OSN to communicate, collaborate and share ideas this could encourage innovation in the organisation. It was further noted that the majority of respondents disagreed or strongly disagreed $(61,2 \%)$ that OSN was strictly associated with teenagers. This result confirmed the respondents' willingness to apply OSN technology which inherently facilitates communication. It could, however, be argued that effective communication methods exist, namely e-mail. In this regard, respondents mainly agreed (57,3\%) that e-mail was as effective as OSN. There was, however, a significant number of respondents who disagreed or strongly disagreed $(26,8 \%)$, thereby indicating their familiarity with the extended benefits of OSN as a communication tool.

Finally the survey investigated respondents' views concerning the potential effect of participating in organisation-specific OSN. Many respondents agreed and strongly agreed $(45,7 \%)$ that such a social network aimed at connecting employees within the organisation would allow them to perform their daily work functions more efficiently. This positive attitude towards organisational OSN should encourage an organisation to exploit OSN technology since the positive effects of CoPs can benefit the organisation in future. However, the findings indicated that the OSN currently occurring at work was not necessarily for work-related purposes, which led this research to the following conclusion.

\section{Conclusion}

Social networking generally stimulates collaboration and knowledge sharing between individuals, which can lead to increased productivity through the creation of CoPs. But OSN technology should be channelled in effective ways to ensure maximum results, as there are pitfalls that employees may succumb to if left to their own strategies. Some of the risks include bandwidth and storage consumption, potential legal liability, exposure to malware, decreased productivity, disclosure of personal information and the risk of leaking corporate secrets. To maximise the potential of OSN within the organisation, it is recommended that organisations designate specific networks for organisation-wide social networking. It is also recommended that employers consider developing and implementing clear and comprehensive acceptable use policies when attempting to deal with OSN issues. This will ensure that employees are aware of what is permitted regarding OSN, what risks are involved from a professional and personal point of view and what the technical implications are. Organisations should therefore establish strategies to address OSN issues such as personal usage, business relevance, site restrictions and information confidentiality without restricting employees to benefit personally as well as professionally from this social Web technology, thereby ultimately benefiting the organisation through its potential positive effect on employee productivity.

\section{References}

Acquaah, M. 2008. Managerial social capital, strategic orientation, and organizational performance in an emerging economy. Strategic Management Journal 28(12):1235-1255. 
Anderson, P. 2007. What is Web 2.0? Ideas, technologies and implications for education. [Online]. Available from: http://www.jisc.org.uk/media/documents/techwatch/tsw0701b.pdf (Accessed 15 August 2008).

Arvanitis, S. and Loukis, E.N. 2009. Information and communication technologies, human capital, workplace organization and labour productivity: a comparative study based on firmlevel data for Greece and Switzerland. Information Economics and Policy 21(1):43 - 61.

Barker, P. 2008. How social media is transforming employee communications at Sun Microsystems. Global Business and Organizational Excellence 27(4):6-14.

Bartlett, C.A. and Ghoshal, S. 2002. Building competitive advantage through people. MIT Sloan Management Review (Winter), 3-42.

Berners-Lee, T. 1 March 2007. Testimony of Sir Timothy Berners-Lee. Hearing on the digital future of the United States: Part 1 - The future of the World Wide Web, before the US House of Representatives Committee on energy and commerce, Subcommittee on telecommunications and the Internet. [Online]. Available from:

http://dig.csail.mit.edu/2007/03/01-ushouse-future-of-the-web.pdf (Accessed 25 August 2008).

Bernoff, J. and Li, C. 2008. Harnessing the power of the oh-so-social Web. MIT Sloan Management Review 49(3):3-42.

Bernolak, I. 1997. Effective measurement and successful elements of company productivity: the basis of competitiveness and world prosperity. International ournal of Production Economics 52:203-213.

Boase, J., Horrigan, J.B., Wellman, B. and Rainie, L. 2006. The strength of Internet ties: the Internet and email aid users in maintaining their social networks and provide pathways to help when people face big decisions. [Online]. Available from:

http://www.pewinternet.org/pdfs/PIP_Internet ties.pdf (Accessed 18 December 2008).

Boothby, R. 2006. The next wave of productivity tools: Web office. [Online]. Available from: http://www.innov ationcreators.com/Web\%20Office\%20White $\% 20$ Paper $\% 20-\% 20$ Rod $\%$ 20Boothby.pdf (Accessed 4 February 2008).

Boyd, D.M. and Ellison, N.B. 2007. Social network sites: definition, history and scholarship. Journal of Computer-mediated Communication 13(1):210-230.

Bryan, L.L., Matson, E. and Weiss, L.M. 2007. Harnessing the power of informal employee networks. The McKinsey Quarterly. [Online]. Available from:

http://www.mckinseyquarterly.com/PDFDownload.aspx?L2=18\& L3=30\&ar=2051/

(Accessed 3 March 2008). Condon, R. 2007. Wiki at work. [Online]. Available from: http://0-proquest.umi.com.ujlink.uj.ac.za/ (Accessed 3 March 2008).

Coyle, C.L. and Vaughn, H. 2008. Social networking: communication revolution or evolution?Bell Labs Technical Journal 13(2):13-17.

European Network and Information Security Agency. 2007. Position paper no. 1: Security issues and recommendations for online social networks. [Online]. Available from: http://www.enisa.europa.eu/doc/pdf/deliverables/enisa_pp_social networks.pdf (Accessed 29 May 2008). 
Golder, S.A., Wilkinson, D. and Huberman, B.A. 2007 . Rhythms of social interaction: messaging within a massive online network. In: C. Steinfield, C., Pentland, B., Ackerman , M. and Contractor, N. (e ds.) Proceedings of Third International Conference on Communities and Technologies. London: Springer.

Groysberg, B. and Lee, L-E. 2008. The effect of colleague quality on top performance: the case of security analysts. Journal of Organizational Behavior 29(8):1123-1144.

Hathi, S. 2008. Billions lost from social networking. Strategic Communication Management 12(2):9. Hong, J., Kianto, A. and Kyläheiko, K . 2008. Movingcultures and the creation of new knowledge and dynamic capabilities in emerging markets. Knowledge and Process Management 15(3):196-202.

KPMG. 2007. Enterprise 2.0: the benefits and challenges of adoption. [Online]. Available from: http://www.kpmg.fi/Binary.aspx? Section=174\&Item=4337 (Accessed 11 April 2008).

Lange, P.G. 2008. Publicly private and privately public: social networking on YouTube. Journal of Computer-Mediated Communication 13(1):361-380.

Lesser, E.L. and Storck, J. 2001. Communities of practice and organisational performance. IBM Systems Journal 40:831-841.

Perkins, B. 2008. The pitfalls of social networking. Computerworld 42(7):44.

Ryberg, T. and Larsen, M.C. 2008. Networked identities: understanding relationships between strong and weak ties in networked environments. Journal of Computer Assisted Learning 24(2):103-115.

Shalley, C.E. and Perry-Smith, J.E. 2008. The emergence of team creative cognition: the role of diverse outside ties, sociocognitive network centrality, and teamvolution. Strategic Entrepreneurship Journal 2(1):23-41.

Khanna, S. and New, J.R . 2008. Revolutionizing the workplace: a case study of the future of work program at Capital One.Human Resource Management 47(4):795-808.

Star Technology. 2008. Online social networking: the employers' dilemma. [Online]. Available from: http://www.star.net.uk (Accessed 28 September 2008).

Tapscott, D. and Williams, A.D. 2007. Wikinomics: how mass collaboration changes everything. New York: Penguin Group.

Vander Veer, E.A. 2008. Facebook: the missing manual. Sebastopol, CA: O'Reilly Media.

Violino, B. 2008. Social networking. AIIM E - Doc Magazine 22(4):12-15.

Ward, T. 2006. Does your Intranet pay its way? In: Melcrum. Transforming your intranet: new techniques in strategy, technology and measurement from the world's leading organisations. Melcrum Publishing: London.

Wenger, E. 2004. Knowledge management as a doughnut: shaping your knowledge strategy through communities of practice. Ivey Business Journal (January/February). [Online]. Available from: http://0-find.galegroup.com.ujlink.uj.ac.za/ (Accessed 28 May 2008).

Wong, S-S. 2008. Task knowledge overlap and knowledge variety: the role of advice 
network structures and impact on group effectiveness. Journal of Organizational Behavior 29(5):591-614.

ISSN 1560-683X

Published by InterWord Communications for Department of Information and Knowledge Management, University of Johannesburg 